\title{
Deformation of chlorite in naturally deformed low-grade rocks
}

\author{
ANTON-JAN BONS * \\ Department of Geology, Institute of Earth Sciences, University of Utrecht, P.O. Box 80.021, 3508 TA Utrecht (The Netherlands)
}

(Received October 5, 1987; revised version accepted March 10, 1988)

\begin{abstract}
Bons, A.-J., 1988. Deformation of chlorite in naturally deformed low-grade rocks. Tectonophysics, 154: 149-165.

The intracrystalline deformation of chlorite in naturally deformed low-grade rocks was investigated with transmission electron microscopy (TEM). As in other phyllosilicates, the deformation of chlorite is dominated by the (001) slip plane. Slip along this plane is very easy through the generation and movement of (partial) dislocations with Burgers vector $b=1 / n[u \nu 0]$. After initial bending of the (001) planes through a flexural slip mechanism, accommodated by slip along (001), the misorientation is concentrated in tiltwalls subnormal to $(001)$, which are formed by (partial) dislocations with $b=1 / n[u \nu 0]$. Tiltwalls subparallel to (001) are formed by arrays of dislocations with a total Burgers vector [001]. These boundaries are either initiated at the grain boundary and move inwards by dislocation climb, or form by movement of free dislocations towards the tip of propagating boundaries by glide along planes inclined to (001); once a boundary is formed, the increasing misfit is accommodated by climb of these dislocations along (001). Due to the combination of very easy slip along (001) and the ability to form subgrain boundaries subparallel to (001) by dislocation climb and activation of hard slip systems, chlorite deforms plastically even at temperatures below $300^{\circ} \mathrm{C}$.
\end{abstract}

\section{Introduction}

The deformation of a rock and its microstructural development are controlled by a number of parameters, one of which is the intracrystalline deformation mechanism of the constituent minerals. Low-grade pelitic rocks are mainly composed of phyllosilicates, in casu mica and chlorite. To understand the deformation of these rocks it is necessary to understand the deformation mechanisms of the phyllosilicates.

Studies of the deformation of phyllosilicates have concentrated almost completely on micas (e.g., Etheridge et al., 1973, 1974; Etheridge and

\footnotetext{
* Present address: Laboratory of Metallurgy, Delft University of Technology, Rotterdamseweg 137, 2628 AL Delft, The Netherlands.
}

Hobbs, 1974; Bell, 1978; Wilson and Bell, 1979; Bell and Wilson, 1981; Bell et al., 1986). Intracrystalline deformation of chlorite has been reported by several authors (e.g., Van der Pluijm and Kaars Sijpesteijn, 1984; Dimberline, 1986; Gregg, 1986), but the intracrystalline deformation mechanism of chlorite is not known in detail. This study aims to describe the intracrystalline deformation of chlorite under (sub)greenschist metamorphic conditions.

\section{Samples}

Two types of deformed chlorite were studied: (1) kinked crystals from the Alps (greenschist facies), and (2) more complexely deformed chlorites in very low-grade slates from the Pyrenees.

The kinked chlorites were collected in the Sesia-Lanzo Zone in the Western Alps, near 
Traversella (Italy). The chlorites were deformed during greenschist facies metamorphism, which took place in the Eocene after the Eo-Alpine high pressure-low temperature metamorphism (Dal Piaz et al., 1972). The crystals are platelets up to a centimetre wide and several millimetres thick. The width of the kink bands is of the order of $200 \mu \mathrm{m}$ (Fig. 1a). EDS analyses indicate a penninite composition (classification of Hey, 1954):

$\mathrm{Mg}_{9.2} \mathrm{Fe}_{1.0} \mathrm{Al}_{1.7}\left[\left(\mathrm{Si}_{6.4} \mathrm{Al}_{1.6}\right) \mathrm{O}_{20} /(\mathrm{OH})_{4}\right](\mathrm{OH})_{12}$

The slate samples were collected in the Seo Slates, Orri Dome, Central Pyrenees, Spain. These rocks are of Cambro-Ordovician age; during Variscan folding a slaty cleavage was developed (Hartevelt, 1970; Speksnijder, 1986). The degree of metamorphism is estimated using illite crystallinity. Illite crystallinity indices, measured using the approach of Kisch $(1980,1983)$, are in the range $0.23-0.30^{\circ}, 2 \theta$. This indicates metamorphism in the anchizone (Kubler, 1967; Kisch, 1983). which corresponds to temperatures of ca. 200-350 ${ }^{\circ} \mathrm{C}$ (Teichmüller et al., 1979). The slate samples consist almost entirely of interlayered muscovite and chlorite. Grain sizes vary from a few microns up to $100 \mu \mathrm{m}$. The average composi-
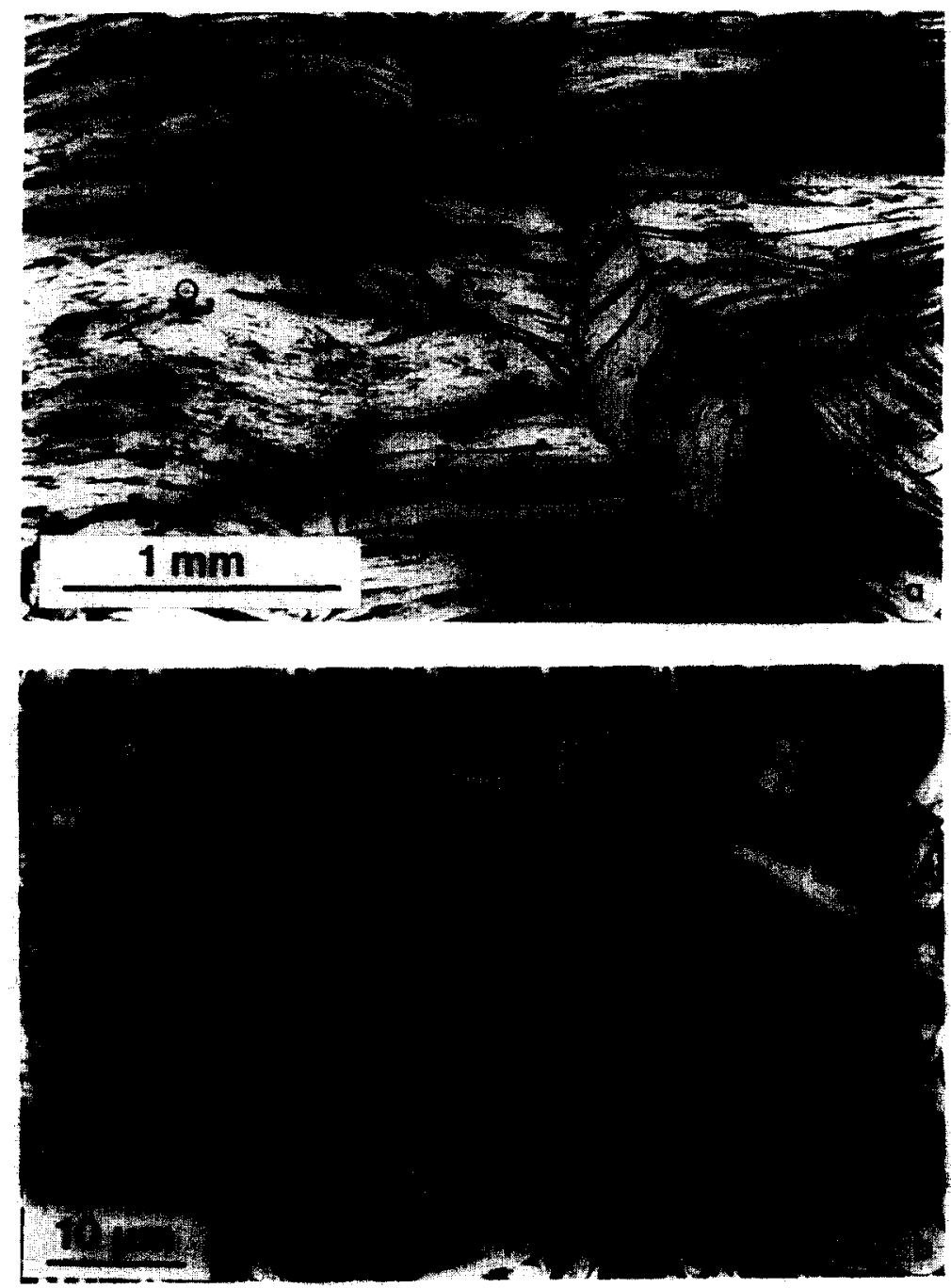

Fig. 1. a. Kinked chlorite crystals from the Traversella region, Italian Alps (plane polarized light). b. Deformed chlorite-mica aggregate in very low-grade slate from the Spanish Pyrenees (crossed nicols). The slaty cleavage is vertical. The chlorite (dark grey) shows undulose extinction on a very small scale, while the muscovite (white) is hardly undulose; new muscovite grains are growing parallel to the cleavage planes, e.g. in region $A$. 
tion of the chlorites in the slate samples is ripidolite:

$\mathrm{Mg}_{3.0} \mathrm{Fe}_{5.5} \mathrm{Al}_{3.3}\left[\left(\mathrm{Si}_{5.2} \mathrm{Al}_{2.8}\right) \mathrm{O}_{20} /(\mathrm{OH})_{4}\right](\mathrm{OH})_{12}$

During slaty cleavage development the chlorite-muscovite aggregates were deformed. The deformation structures inside the chlorite include undulose extinction, folds, and low- and high-angle boundaries within grains (Fig. 1b). The muscovite shows folds and kinks, but the grains show hardly any undulose extinction (see also Gregg, 1986). Serrated kink band boundaries and new muscovite grains growing into deformed grains indicate that migration recrystallization dominates during the deformation of muscovite at these conditions.

Truncation of grains, and reduction of the quartz content in areas of strong cleavage development in layers which are otherwise rich in quartz, indicate that pressure solution processes were active during slaty cleavage formation. Nevertheless, the extensive internal deformation of the chloritemica aggregates indicates that it was only of minor importance to the deformation of the phyllosilicates.

\section{Methods}

For the TEM study selected areas from thin sections were fixed to copper support grids and thinned down to perforation by ion beam milling. The samples were then coated with carbon and studied in a JEOL $200 \mathrm{C}$ electron microscope, fitted with a side-entry goniometer stage, operating at $200 \mathrm{kV}$.

Often the dislocations were so closely spaced that they could not be resolved by conventional bright field (BF) or dark field (DF) methods. The techniques that have been used in this case are weak beam imaging (WB) and high resolution electron microscopy (HREM). During HREM axial illumination was used, i.e. the transmitted beam lies on the optic and the diffracted beams are symmetrically disposed about it, so that the position of the resulting lattice fringes is independent of crystal thickness (Edington, 1975).

\section{Crystal structures}

The intracrystalline deformation of phyllosilicates is dominated by the highly anisotropic crystal

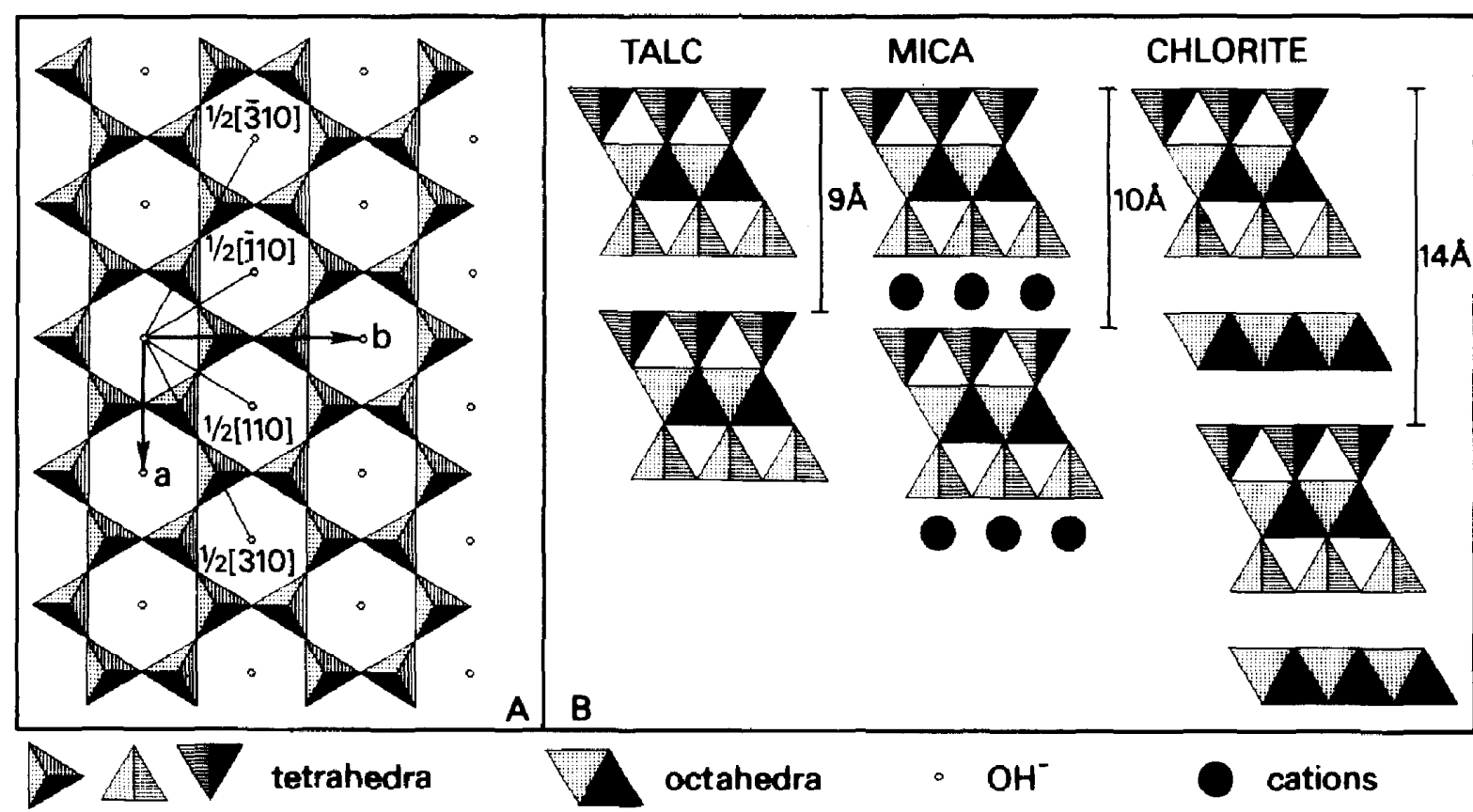

Fig. 2. Crystal structure of chlorite. A. Tetrahedral sheet; the crystal axes $a$ and $b$ are indicated, together with their equivalent directions (a-axis: $\pm[110]$ and $\pm[110] ; b$-axis: $\pm[310]$ and $\pm[\overline{3} 10]$ ). B. Schematic representation of the structure of talc, mica and chlorite, projected parallel to the $b$-axis. See text for further details. 
structure; therefore a brief description of the crystal structure will be given below. For a more detailed description and for further references the reader is referred to the literature (e.g., Bailey, 1975, 1984).

The basic structure of all phyllosilicates is a sheet of $(\mathrm{Si}, \mathrm{Al}) \mathrm{O}_{4}$-tetrahedra linked together in a pseudo-hexagonal pattern (the tetrahedral sheet or T-sheet), in which the $a$-and $b$-axes lie (Fig. 2A). In the group of $2: 1$-phyllosilicates, to which talc, mica and chlorite belong, two of these tetrahedral sheets are sandwiched together to form a sheet of octahedral sites in between (the octahedral sheet or O-sheet). The octahedral sites can be occupied by various metal ions. This packet of tetrahedraloctahedral-tetrahedral sheets is often called the "talc" layer or T-O-T layer, although the term " $2: 1$ layer" is preferable (Bailey, 1980). The $2: 1$ layers are stacked in the direction of the $c$-axis with or without interlayers.

Because of the pseudo-hexagonal symmetry of each sheet, every direction in the $(001)$ plane has more or less equivalent directions at $60^{\circ}$ intervals. For example, the equivalent directions for [100] are [110] and [ 110$]$, and the equivalent directions for [010] are [310] and [310] (Fig. 2a).

In talc the 2:1-layers are electrostatically neutral and they are stacked in the direction of the $c$-axis without any layer in between. In the case of micas the electrical charge of the $2: 1$ layer is compensated by an interlayer of cations (Fig. 2B).

The chlorite structure consists of alternating 2: 1-layers and brucite-like $\mathrm{Mg}$, Fe-hydroxide interlayers. A single chlorite unit is formed by one 2:1-layer and one interlayer; the total thickness is about $14 \AA$ (Fig. 2B). Brown and Bailey (1962) determined that four different structural units, consisting of four different relative arrangements of $2: 1$ - and interlayers are theoretically possible. These structural units can be stacked in various ways, leading to a large number of regular onelayer polytypes. However, many chlorites have irregular stacking sequences. In diffraction patterns they show sharp $k=3 n$ reflections and continuous streaking of the $k \neq 3 n$ reflections, indicating that the layers are related to one another by shifts of magnitude $b / 3$ and still maintain hydrogen bond contact. This is termed semi-random stacking (Brown and Bailey, 1962; Bailey, 1975). The shifts can occur both at the level of the interlayer and within the 2:1 layer (Spinnler et al., 1984; Bons and Schryvers, 1988).

\section{Deformation of phyllosilicates}

Because the crystal structure of chlorite is closely related to that of talc and micas, it is convenient to discuss the deformation of chlorite in view of what is already known about the deformation of the other phyllosilicates.

Studies of phyllosilicate deformation have concentrated mainly on micas. Many experimental studies have shown that the slip plane is (001) and that the dominant slip directions are [100], $\pm[110]$ and $\pm[\overline{1} 10]$ (Mügge, 1898; Griggs et al., 1960; Borg and Handin, 1966; Hörz and Ahrens, 1969; Hörz, 1970; Schneider, 1972; Etheridge et al., 1973). Early studies on dislocations in mica have reported dislocations parallel to the $(001)$ plane with Burgers vectors $b=[100], b=1 / 2[110]$ and $\boldsymbol{b}=1 / 2[\overline{1} 10]$, without any visible dissociation (Silk and Barnes, 1961; Amelinckx and Delavignette, 1962; Demny, 1963a); these dislocations occur in the cation interlayer, where dissociation into partials is unlikely (Olives, 1985). These dislocations are not mobile in the electron microscope, not even when the foil is heated (Silk and Barnes, 1961).

Bell and Wilson $(1977,1981,1986)$ have reported stacking faults and dislocations in muscovite and biotite. The stacking faults were the result of both crystal growth processes and deformation. The observed stacking fault vectors were $\pm 1 / 3$ [010], $\pm 1 / 6[310]$ and $\pm 1 / 6[310]$. These stacking faults were supposed to occur in the octahedral sheet of the 2:1-layer without significant increase in energy, rather than in the cation interlayer. where the increase in energy would be considerable (Bell and Wilson, 1977; Olives, 1985). The dislocations were all contained in the (001) plane; some of the dislocations were clearly dissociated into partials with stacking faults inbetween. In regions where the mica lattice was gently curved slip occurred parallel to (001) by the generation and movement of (partial) dislocations, and subgrains were developed, bounded by dislocation 
walls subparallel and subnormal to (001). With increasing rotation the strain was no longer accommodated by dislocation creep but dilation along the (001) cleavage plane occurred. This deformation mechanism is thought to be typical for crystalline materials with only one active slip plane (Nicolas and Poirier, 1976; Bell and Wilson, 1981; Bell et al., 1986).

Amelinckx and Delavignette (1962) studied deformed talc crystals with TEM. They observed dislocations with Burgers vectors $\boldsymbol{b}_{\text {tutal }}=[100]$, $\boldsymbol{b}_{\text {total }}=1 / 2[110]$ and $\boldsymbol{b}_{\text {total }}=1 / 2[1 \overline{1} 0]$, dissociated into wide dislocation ribbons of four partial dislocations; the Burgers vectors of the partials are $b_{\mathrm{p}}= \pm 1 / 6$ [010], $\boldsymbol{b}_{\mathrm{p}}= \pm 1 / 12$ [310] and $\boldsymbol{b}_{\mathrm{p}}=$ $\pm 1 / 12$ [310]. These dislocations, and the associated stacking faults, occur inbetween the 2:1layers, where stacking fault energy is very low due to the weak bonds between the layers.

It is clear that the deformation of phyllosilicates is dominated by the (001) slip plane, while slip directions are parallel to [100], [010] and other directions which are equivalent due to the pseudo-hexagonal symmetry in the (001) plane. The slip can take place either at the level of the octahedral sheet of the $2: 1$-layer or inbetween the 2 : 1-layers.

\section{TEM observations}

\section{Practical aspects of the TEM observation of chlorite}

Most phyllosilicates are rapidly damaged by the electron beam (Demny, 1963b; Bell and Wilson, 1981; Ahn et al., 1986). Indeed, the muscovites in the slate samples were very sensitive to radiation damage and were destroyed within seconds. The chlorites, however, were relatively stable and could be studied for several minutes.

All chlorites studied show sharp $k=3 n$ reflections and streaked $k \neq 3 n$ reflections, which indicates that they have a semi-random stacking sequence (Brown and Bailey, 1962; Bailey, 1975). Many electron micrographs of chlorite show a diffuse contrast of overlapping fringes in the background (see e.g. Fig. 3). This is the case in almost all micrographs where the (001) plane is inclined to the electron beam, but it is never observed in cases where (001) is perpendicular or parallel to the beam. It is most likely that the fringe contrast is caused by the stacking disorder: the irregular offsets of chlorite layers are essentially the same as stacking faults and give rise to fringe contrast if the (001) plane is inclined to the beam. Because of the close spacing between the offsets the fringes overlap and give the complex background contrast observed. This background contrast seriously hampers the interpretation of the lattice defects.

Although the radiation damage rate is lower than in micas, there still is little time for tilt experiments, which makes it difficult to do a complete Burgers vector analysis of the dislocations. Another problem is the difficulty of obtaining two-beam conditions. This effect is typical for strongly layered materials with weak bonds between the layers. During electron diffraction each layer acts as a single crystal with almost zero thickness. Every diffraction spot is thus extended into a "spike" in reciprocal space, and will intersect the Ewald sphere even at very large deviations from the Bragg angle. If (001) is at a large angle to the electron beam the spots of a strong reflection zone remain visible even after tilting over several tens of degrees. The diffraction pattern itself becomes distorted and cannot be properly indexed; therefore these orientations cannot be used for quantitative analysis of dislocations.

\section{Deformation structures}

In the kinked chlorite crystals three deformational domains can be distinguished: (1) the areas outside the kinkbands, (2) the areas inside the kinkbands and (3) the kink hinges. The rotation axes of the kinkbands lie in the (001) plane. Electron diffraction patterns of the kinkband of Fig. 1a and Fig. 3 show that the rotation axis is parallel to [100].

In the areas outside the kinkbands the crystal lattice is straight (Fig. 3a). Dislocation density is low to moderate $\left(<3 \cdot 10^{8} \mathrm{~cm}^{-2}\right)$. The dislocations are usually arranged in dislocation bands; apart from this the dislocations are homogeneously distributed throughout the crystal and no subgrains have developed. The areas inside the kinkbands show much higher dislocation densities 

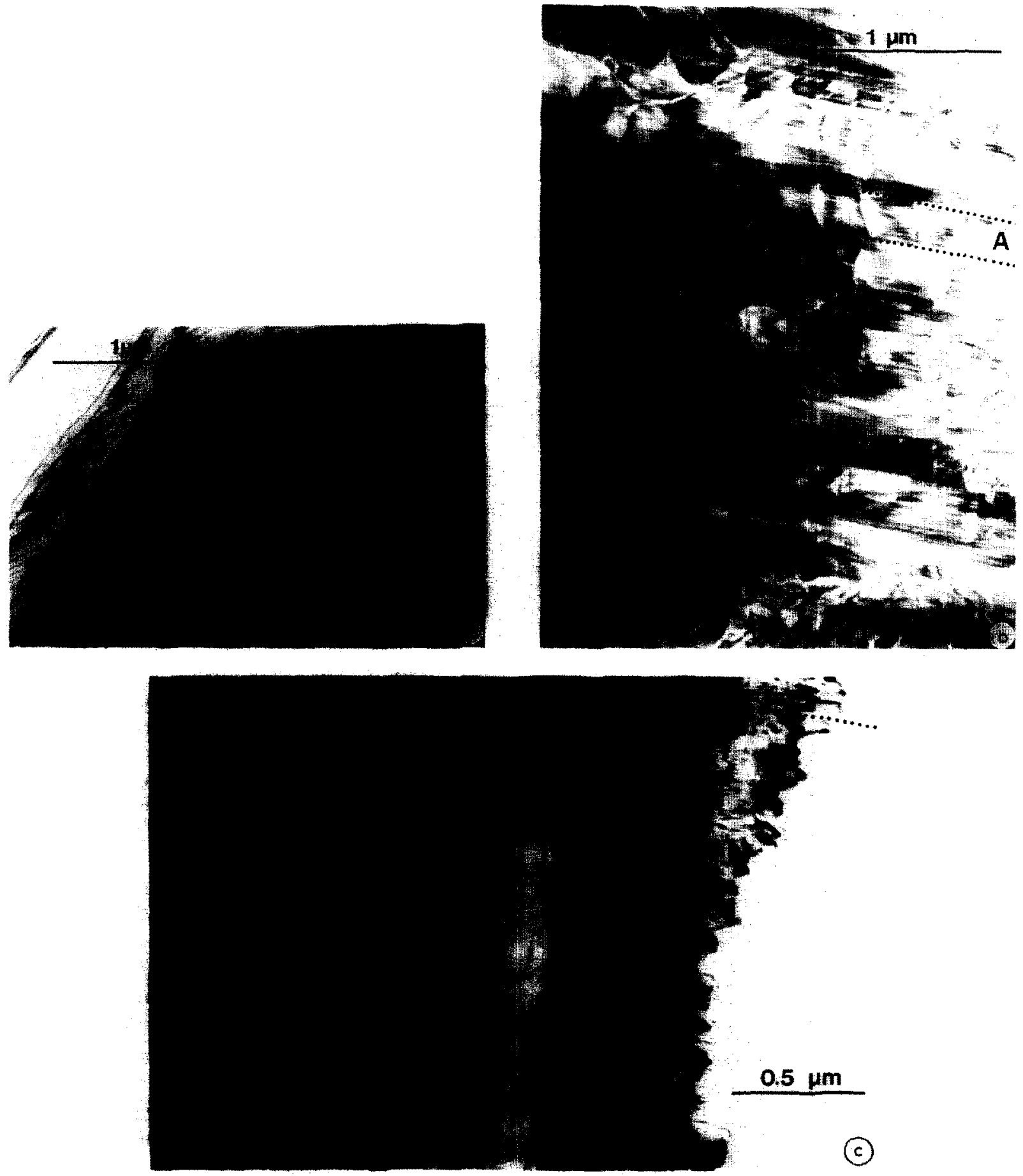

Fig. 3. Dislocations in the kinked chlorite crystal of Fig. 1a.

a. BF transmission electron micrograph of an area outside the kinkband; dislocation density is low. A single dislocation band is visible between the arrows. The background fringe contrast, caused by the stacking disorder of the crystal, is parallel to the (001)-trace.

b. DF micrograph of an area inside the kink band, showing a much higher dislocation density. Dislocations are arranged in dislocation bands; one dislocation band is indicated by $A$. Dotted lines indicate the intersections between the dislocation band $A$ and the upper and lower surfaces of the thin foil. No subgrain walls have developed

c. BF micrograph of the kink hinge area; the $(001)$-trace is indicated by black dotted lines. Dislocation density is very high; dislocation walls subnomal to (001) (short arrows) and subparallel to (001) (long arrow) are visible. 

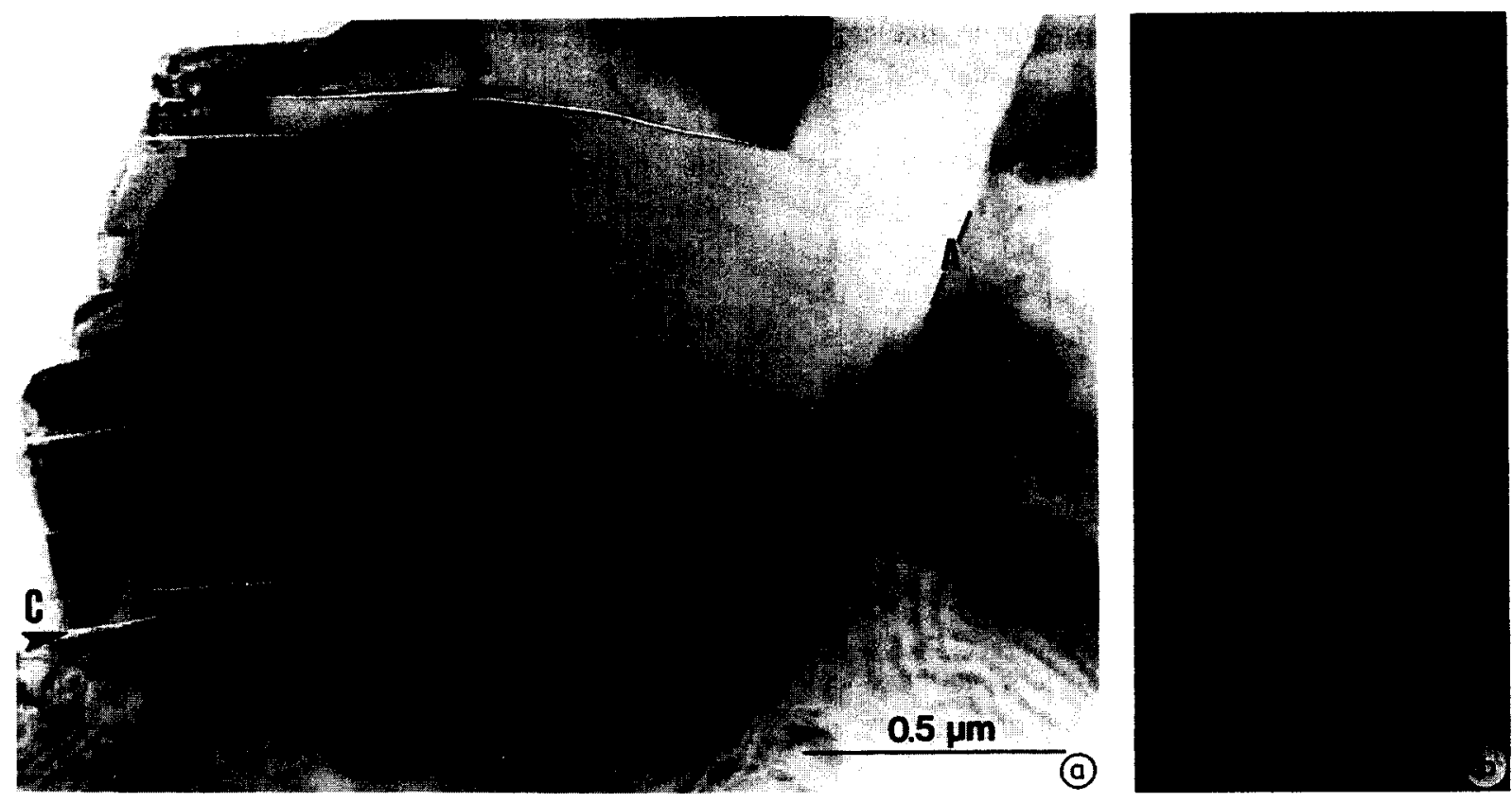

Fig. 4. Subgrains in deformed chlorite from one of the slate samples. a. BF micrograph of subgrains with boundaries subnormal ( $A$ ) and subparallel $(B)$ to $(001)$; the dilation parallel to the $(001)$ cleavage planes is caused by electron beam irradiation. The arrow at $C$ indicates a boundary along which the misfit decreases from $30^{\circ}$ at the grain boundary to $0^{\circ}$ inside the crystal. b. Selected area diffraction pattern of $00 \mathrm{l}$ reflections showing discrete rotations of the crystal.

$\left(>2 \cdot 10^{9} \mathrm{~cm}^{-2}\right)$, but the dislocations are still homogeneously distributed and subgrains are absent (Fig. 3b).

Detailed study of the kink hinges (Fig. 3c) reveals that the rotation takes place over a wider area, instead of in one discrete kink as has been assumed in crystallographic models of kink bands in micas (Starkey, 1968; Baronnet and Olives, 1983). Bell et al. (1986) observed the same thing in kinked mica crystals. In chlorite the kink hinge zone is a few microns wide and it is divided into subgrains. Within each subgrain the crystal is only very slightly bent. At the subgrain boundaries there is a rotation of about $2^{\circ}$. The subgrain boundaries show two preferred orientations: (1) subparallel to (001) and (2) subnormal to (001). In these areas the dislocation density is so high that the individual dislocations cannot be distinguished. Apart from dilation during electron beam irradiation (Fig. 4a), no dilation along (001) planes has been observed.

The deformed chlorites from the slate samples show similar structures. In areas where the crystal is not bent dislocation densities are low, and dislo- cations are evenly distributed through the crystal. If the crystal is bent subgrains are developed, with subgrain boundaries subnormal and subparallel to (001), and dislocation density is very high. The discrete rotations between subgrains are also clearly visible in electron diffraction patterns (Fig. 4b).

\section{Individual dislocations}

When dislocations are imaged using HREM two types of dislocations can be distinguished: (1) dislocations associated with terminating (001) lattice fringes, and (2) dislocations that do not affect the (001) lattice fringes. Because their Burgers vectors can be written in a general form as $[00 w]$ and [uv0] (see below), these two groups will be referred to as $[00 w]$ and [uv0] dislocations, respectively.

(a) [uv0] dislocations. In general the dislocation densities are low where the (001) planes are straight. Most of the dislocations in these areas are of the [uv0] type. When the foil is heated by 
concentrating the electron beam on a small area the $[u v 0]$ dislocations become mobile and start moving parallel to the (001) plane.

Although a complete Burgers vector analysis was not achieved, some general information on the Burgers vector directions could be obtained. In lattice fringe images of $[u v 0]$ dislocations the (001) fringes are continuous, indicating that these dislocations do not affect the (001) planes. Furthermore, these dislocations are always out of contrast if the operating reflections are of the form $00 l$. This indicates that the Burgers vectors have no component in the direction of the $c$-axis, and can therefore be written in a general form as $\boldsymbol{b}=[u v 0]$.

Figure 5 shows two DF-images of [ $u v 0]$ dislocations taken under two-beam conditions. There are three groups of dislocations:

(1) dislocations visible for both $\boldsymbol{g}=[134]^{*}$ and $\boldsymbol{g}=[1 \overline{3} \overline{2}]^{*}$;
(2) dislocations visible for $g=[134]^{*}$ but invisible for $g=[1 \overline{3} \overline{2}]^{*}$;

(3) dislocations visible for $g=[1 \overline{3} \overline{2}]^{*}$ but invisible for $g=[134]^{*}$, where $g$ is the vector normal to the reflecting plane. Using the invisibility criterion:

$\boldsymbol{g} \cdot \boldsymbol{b}=0$

and taking into account that the Burgers vectors lie in the (001) plane, this means that there are at least three different Burgers vectors, with directions $\pm[310], \pm[3 \overline{1} 0]$ and $[u v 0](u \neq \pm 3 v)$.

Sometimes the $[u v 0]$ dislocations are associated with planar defects; these planar defects are parallel to (001). Generally the nature of planar defects can be analysed using the fringe pattern which is visible when the defect plane is inclined to the beam (see, e.g., Edington 1975). Unfortunately this was not possible in the chlorites, due to the omnipresent background fringe contrast described
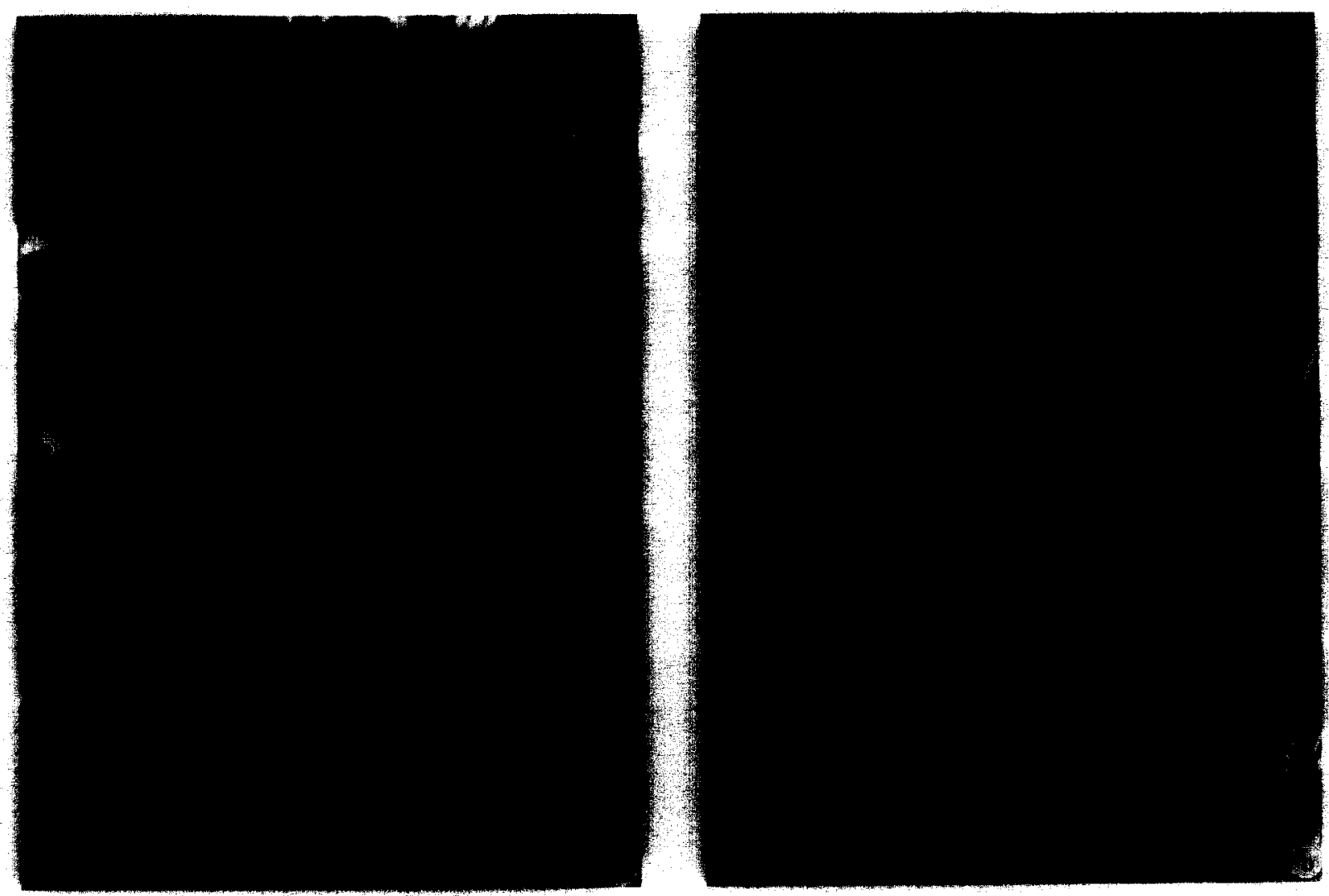

Fig. 5. Example of a contrast analysis of $[u v 0]$ dislocations. a. $g=[1 \overline{3} \overline{2}]^{*}$; several dislocations are visible, e.g. the cluster around $A$. b. $g=[134]^{*} ;$ the dislocations around $A$ are now out of contrast. The background fringe contrast is parallel to the (001) trace. 
above. This problem is presently being investigated with HREM.

(b) $[00 \mathrm{w}]$ dislocations. The other type of dislocation is associated with terminating (001) lattice fringes, which indicates that their Burgers vector has a component in the direction of the $c$-axis. Under special conditions (dislocation parallel to the beam, axial illumination; see Edington, 1975) terminating lattice fringes may be interpreted as terminating lattice planes; therefore these dislocations can be described as edge dislocations with a total Burgers vector $\boldsymbol{b}=[001]$. Similar dislocations have been described by Knipe (1981), Lee et al. (1984, 1986), Ahn and Peacor (1985) and Bell (1986).

\section{Dislocation walls}

At the subgrain boundaries the dislocations are so close to each other that they cannot be resolved using conventional BF or DF techniques. However, WB or HREM images show that these boundaries are formed by arrays of dislocations (Figs. 6 and 7).

One group of subgrain boundaries is oriented at a very high angle to (001) (Fig. 6). The misorientation across the walls is in the range of $1-3^{\circ}$. The dislocations that form the boundary are contained in the (001) plane and they are always parallel to [100], [010], and equivalent directions. Lattice fringe images show that the $(001)$ planes are continuous across the boundaries (Fig. 6b), indicating that the dislocations are of the type [uv0]. Invisibility of the dislocations for $00 l$ reflections confirms this. Diffraction patterns (Fig. 4b) and lattice fringe images (Fig. 6b) show that the walls are pure tilt walls and that the rotation axes are parallel to the dislocation lines. This indicates that the dislocations are pure edge dislocations, and that their Burgers vectors are parallel to [010], [100], and equivalent directions.

The other group of subgrain boundaries is subparallel to (001) (Fig. 7). HREM images show that
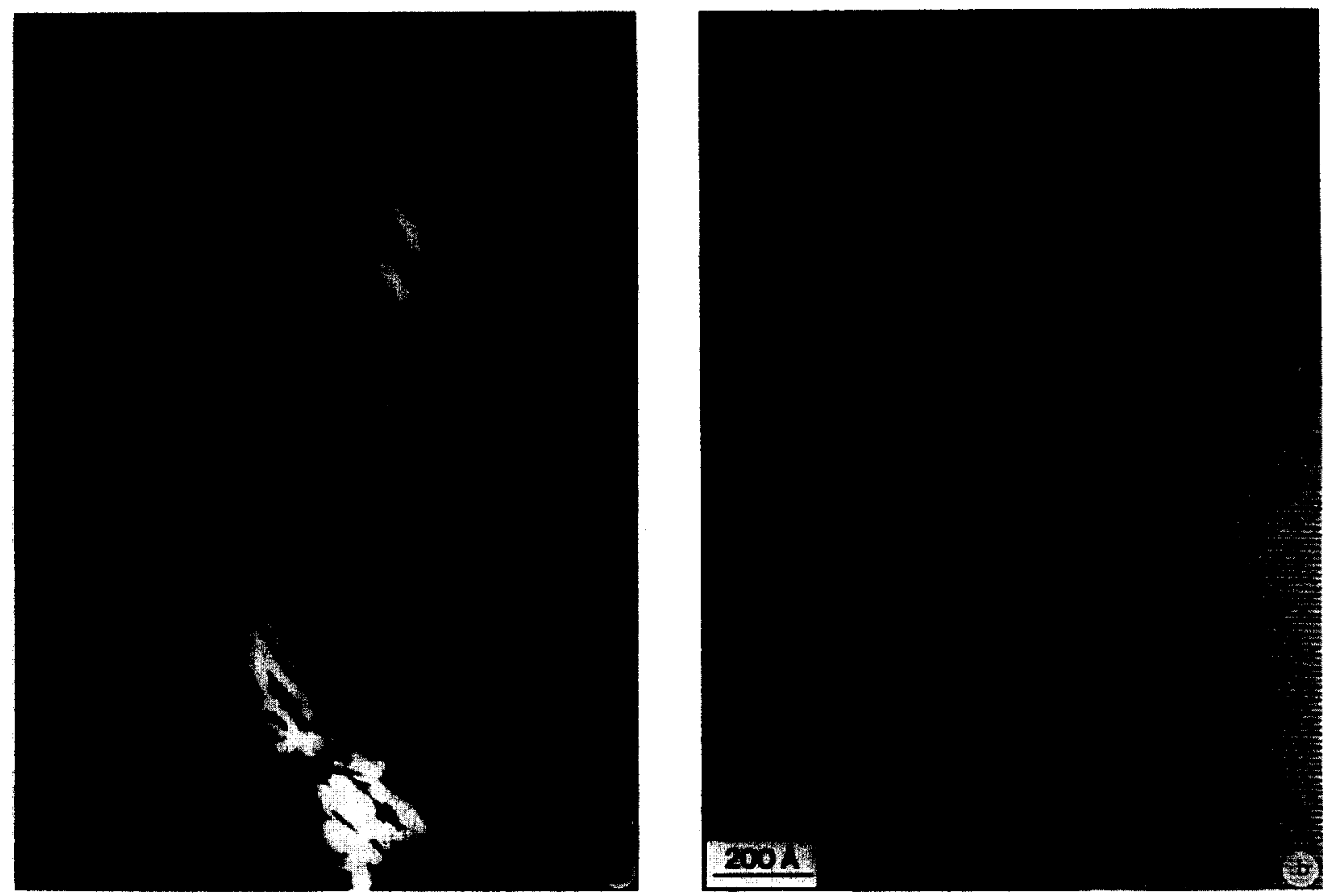

Fig. 6. a. WB image of a tilt wall subnormal to (001); the dislocation lines are parallel to [110]. The spacing of the dislocations along the wall is variable. The (001) trace is indicated. b. HREM image of the boundary showing continuous (001) lattice fringes. 

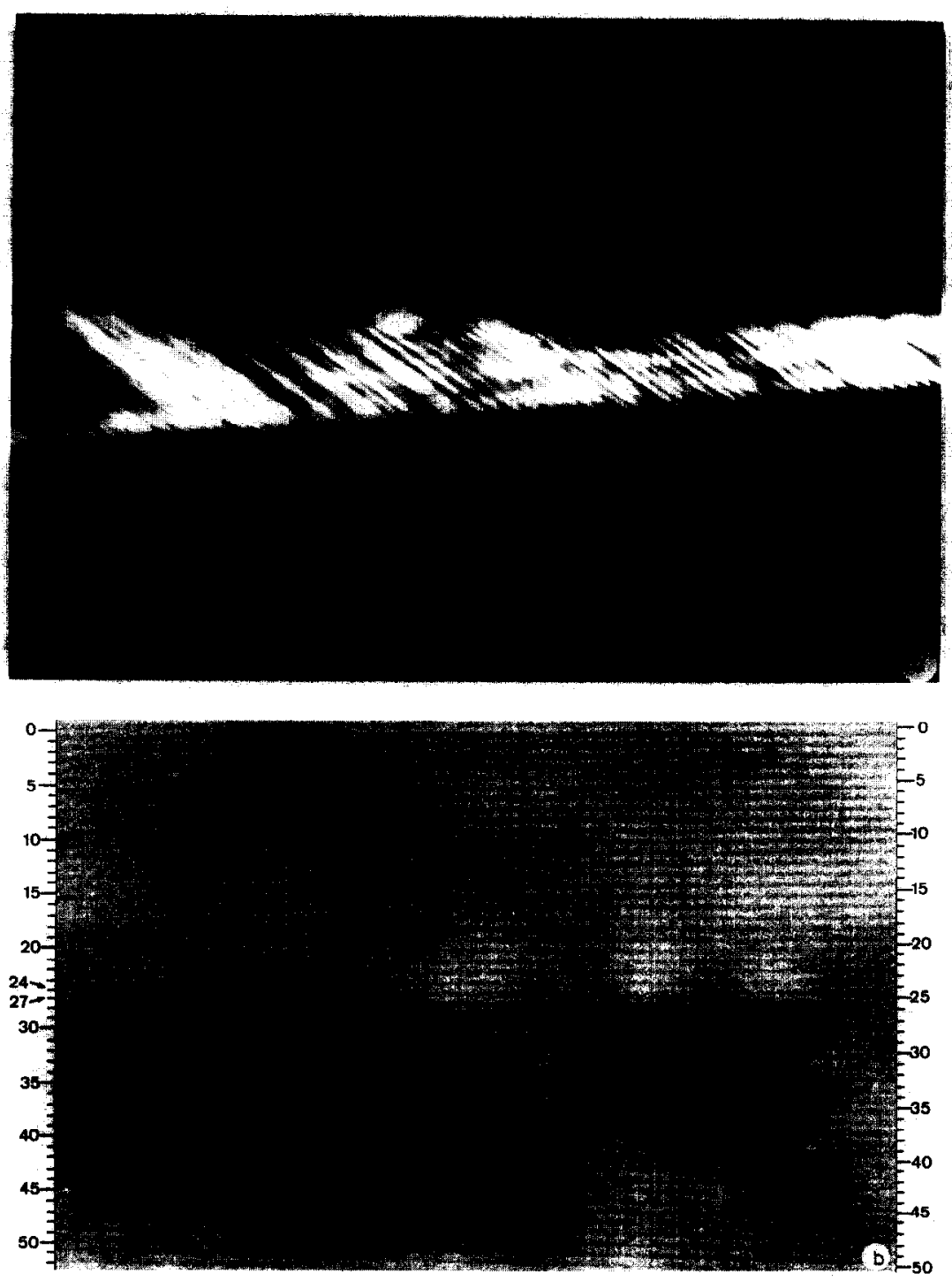

Fig. 7. a. WB micrograph of a dislocation wall subparallel to (001). The spacing between the dislocation lines is on the order of 0.01 $\mu \mathrm{m}$. b. (001) lattice fringe image of the boundary. The bright fringes are numbered on both sides of the picture. Fringes 25 and 26 gradually wedge out from right to left; this can best be seen by viewing the page at a glancing angle in a direction parallel to the fringes.

they are formed by a series of terminating crystal layers (Fig. 7b). These layer terminations can be described as edge dislocations with Burgers vector $\boldsymbol{b}=[001]$. If the boundary is inclined to the beam, the dislocations become visible (Fig. 7a). The spacing between the dislocations is very small. In the case of Fig. 7a the spacing is on the order of $100 \AA$. Measurements on lattice fringe images indicate an angle of misfit between $2^{\circ}$ and $3^{\circ}$.
Because the boundary is asymmetric, the equation:

$|\boldsymbol{b}| / d=\sin \theta$

applies (where $|\boldsymbol{b}|=$ length of the Burgers vector, $d=$ spacing between dislocations, and $\boldsymbol{\theta}=$ angle of misfit; Hull and Bacon, 1984) indicating that the Burgers vector has a magnitude on the order of 3-4 $\AA$, which is much smaller than the unit vector of $14 \AA$. The presence of partial dislocations along 

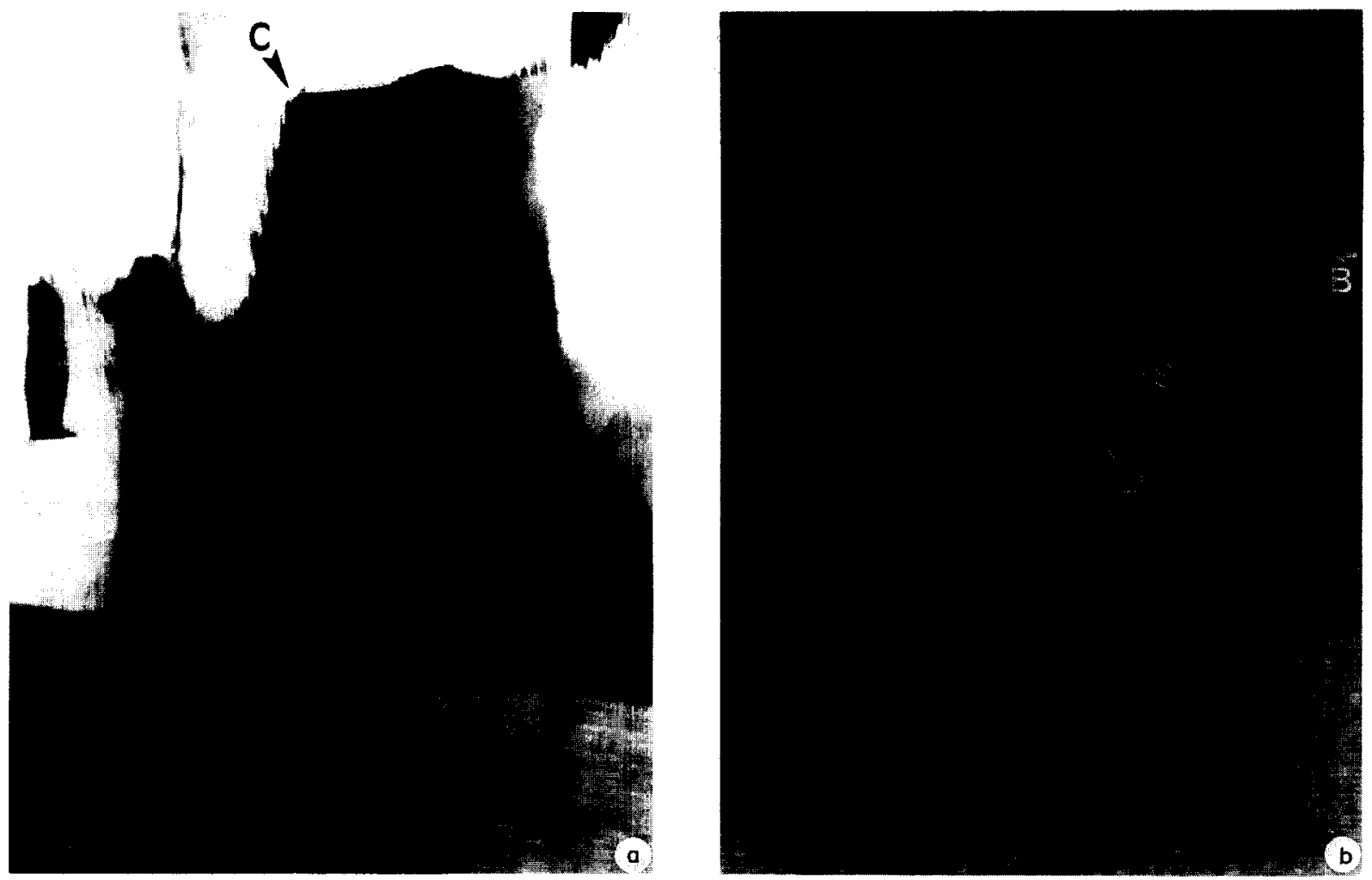

Fig. 8. a. Subgrains in deformed chlorite; subgrain boundaries are subnormal $(A)$ and subparallel $(B)$ to $(001)$. The arrow at $C$ indicates the tip of a propagating boundary where there is a cluster of $[00 w]$ dislocations. $b$. (001) lattice fringe image of the cluster of $[00 w]$ dislocations at the tip of the subgrain boundary; $B=$ subgrain boundary, $D=$ dislocation. The strain fields $(S)$ of the dislocations are visible as regions with high contrast; the strain fields extend from one dislocation to another.

these subgrain boundaries has been confirmed by HREM (Zwart and Bons, 1987).

The subgrain boundaries subparallel to (001) often terminate inside the crystal. Usually there is a cluster of $[00 w]$ dislocations just ahead of the tip of the boundary (Fig. 8).

Both types of subgrain boundaries can grade into high-angle boundaries. Along boundaries subparallel to (001) the misfit can increase within one micron from zero to more than $30^{\circ}$ (Fig. $4 \mathrm{a}$ ).

\section{Discussion}

\section{Dislocations and dislocation walls}

In the previous section it has been shown that there are two groups of dislocations: [ $u v 0]$ dislocations and $[00 w]$ dislocations. These two groups will be discussed separately. (a) [uv0] dislocations. Both the dislocation lines and the Burgers vectors of these dislocations are contained in the (001) plane. As in talc and mica, the Burgers vectors are parallel to [100], [010], and equivalent directions. The magnitude of the Burgers vectors is unknown. Regarding the magnitude of the unit displacement vectors, which vary from $5.2 \AA$ for $b=[100]$ to $9.2 \AA$ for $b=$ [010], it is unlikely that they are unit dislocations (although unit dislocations with $\boldsymbol{b}=[100](5.2 \AA)$ do occur in the cation layer of micas-Silk and Barnes, 1961; Amelinckx and Delavignette, 1962; Demny, 1963a). If they are partial dislocations, they would be expected to be associated with stacking faults. However, only a few of the dislocations are visibly associated with a planar defect.

In this context, it is necessary to consider the consequences of the stacking disorder. The stacking disorder itself is caused by displacements of 
$b / 3$, which take place both within the $2: 1$ layer and at the interlayer (Spinnler et al., 1984; Bons and Schryvers, 1988). Because most chlorites have disordered stacking sequences, displacements of $1 / 3$ [010] (or its equivalents $1 / 6$ [310] and 1/6 [310]) can apparently occur without any increase in energy. If, due to deformation, partial slip occurs along (001) over a distance $b / 3$ in one of the appropriate directions, the resulting crystal would not have a higher energy state than before. The plane where the partial slip was induced would not differ from any other plane where the offset of $b / 3$ was an original feature of the crystal (Fig. 9b), and it would therefore not show any additional contrast. In the case where slip is restricted to a limited area within one (001) plane, the area of slip would be bounded by dislocations. Although these dislocations are partial dislocations, the surface in between can hardly be called a stacking fault. Also, the sum of the partial dislocations would not necessarily be a unit vector. Only those stacking faults which have a displacement vector other than $b / 3$ will give rise to a visible planar defect, although the contrast will bc obscured by the background contrast.

Most of the observed dislocations, including those of Fig. 5, are not visibly associated with stacking faults; often the Burgers vectors are parallel to [010] or equivalent directions. In view of what was stated above these dislocations can be interpreted as partial dislocations with Burgers vectors $\boldsymbol{b}= \pm 1 / 3$ [010], $\boldsymbol{b}= \pm 1 / 6$ [310] and $\boldsymbol{b}=$ $\pm 1 / 6[\overline{3} 10]$. The few dislocations which are visibly associated with stacking faults either have a displacement of $b / 3$ in an area with a (short-range) regular stacking sequence, or have a totally different displacement vector, e.g. with direction [100]. The tilt walls with Burgers vector directions [100] are possibly formed by unit dislocations, because no stacking faults are visible on either side.

(b) $[00 w]$ dislocations. Every chlorite crystal shows some free $[00 w]$ dislocations. In regions with straight (001) planes the dislocation density is low; if the crystal is bent the dislocation density is much higher and tiltwalls subparallel to (001) are formed.

The formation of dislocation walls requires the generation and/or movement of dislocations. Figure 10 shows two different models for the formation of a $[00 w]$ dislocation wall. In model $\mathrm{A}$ a number of [001] dislocations is distributed evenly throughout the undeformed crystal. Such dislocations have been observed frequently in phyllosilicates, especially in diagenetic and anchimetamorphic rocks (Knipe, 1981; Lee et al., 1984, 1986; Ahn and Peacor, 1985; Ahn et al., 1985: Bell,
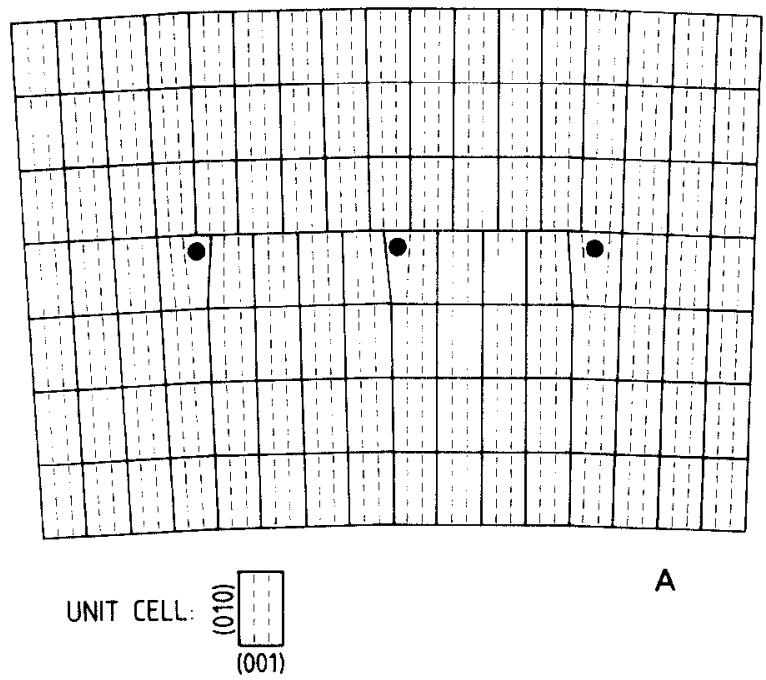

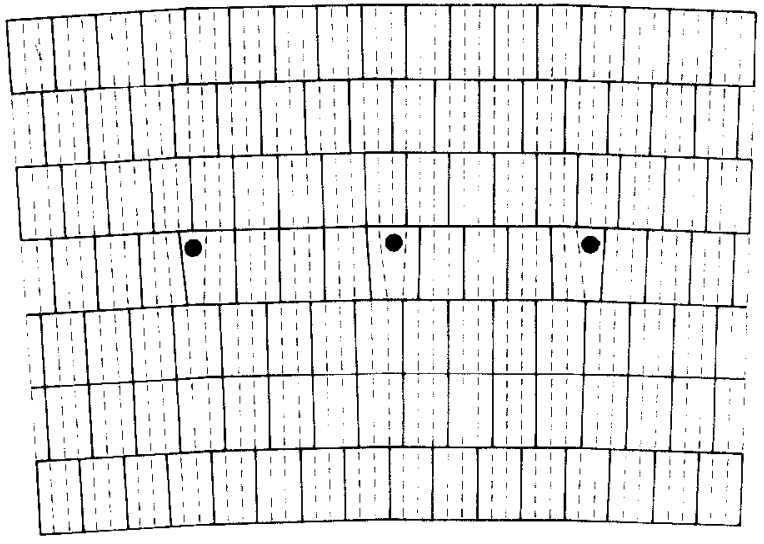

B

Fig. 9. Schematic representation of partial dislocations with $\boldsymbol{b}=1 / 3$ [010]. The black dots indicate dislocation cores. A. A crystal with a regular stacking sequence; there are stacking faults in between the dislocations. B. A crystal with stacking disorder; the crystal structure in between the partial dislocations does not differ from the overall crystal structure and no stacking faults will be visible. 

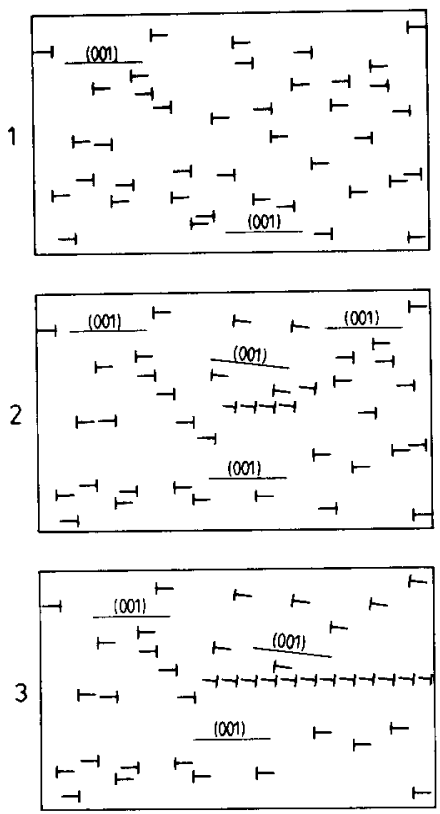

A
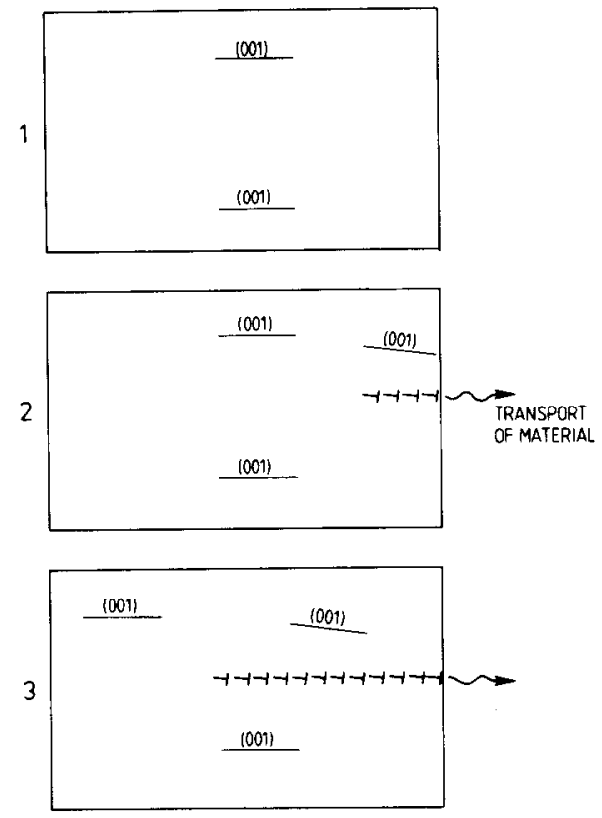

B

Fig. 10. Two models for the formation of [00l] dislocation walls. Model A: dislocations which are originally evenly distributed throughout the crystal move towards the boundary by slip along $(h k 0)$ planes. Model B: dislocations nucleate at the grain boundary and move into the crystal by climb, which involves transfer of material. Most boundaries are formed by a combination of these two processes. $(001)=(001)$-trace; $-1=$ edge dislocation.

1986). If the crystal is strained the dislocations start to move and align themselves in a dislocation wall subparallel to (001). The movement of dislocations involves slip on $(h k 0)$ planes and climb along (001). In model $B$ the dislocations nucleate at the edge of a perfect crystal, and move into the crystal by climb along (001). The surface of the crystal acts as a vacancy source. This process involves transport of material by diffusion along the boundary. In both models an increasing misfit across the boundary is accommodated by increasing the dislocation density along the boundary.

The TEM observations on chlorite indicate that both models for the formation of $[00 w]$-dislocation walls may apply. Many boundaries, such as the boundaries in Fig. 4a, run from high-angle boundaries at the surface of the crystal into lowangle boundaries inside the crystal, and terminate somewhere inside the crystal. Apparently one section of the crystal is displaced relative to the rest of the crystal (cf. Gregg, 1986, fig. 2a); the strain is accommodated by the formation (and subse- quent movement by climb) of $[00 w]$ dislocations (Model B).

Other subgrain boundaries do not reach the crystal surface (e.g. Fig. 8). At the tip of these boundaries there are often clusters of $[00 w]$ dislocations (Fig. 8b); this geometry can be interpreted in terms of dislocations moving towards the tip of the boundary. This involves dislocation glide along $(h k 0)$ planes. The absence of bands of $[00 w]$ dislocations along $(h k 0)$ planes indicates that it is not an easy slip plane. The strain contrast around the dislocations in Fig. $8 \mathrm{~b}$ extends from one dislocation to another, indicating that not only the strain field, but also the stress field extends from one dislocation to the other. Apparently the stresses at the tip of the subgrain boundary are large enough to activate hard slip systems.

Most subgrain boundaries show characteristics of both models shown in Fig. 10; they have reached a high-angle stage at the crystal surface, grade into a low-angle boundary inside the crystal and terminate in a cluster of $[00 w]$ dislocations. Thus 
it can be concluded that usually both mechanisms of subgrain boundary formation operate simultaneously.

The fact that intermediate stages of the development of subgrain boundaries are preserved in these samples indicates that the propagation of a wall is relatively slow, even if the wall has developed into a high-angle boundary some distance away. The termination of a subgrain boundary inside a crystal leads to long-range stress fields at the tip of the boundary (Hull and Bacon, 1984). In materials with multiple slip systems (e.g., metals, quartz, olivine) these stress fields are reduced by rapid propagation of the boundary by the attraction of free dislocations, and no intermediate stages are observed (e.g., White, 1971; Boland et al., 1971. Takeuchi and Argon, 1976; Hull and Bacon, 1984). In chlorite the subgrain boundary can reach a relatively high angle of misfit before the stresses at the tip of the boundary are large enough to activate the hard $(h k 0)$ slip systems.

Both conventional TEM images and HREM images of $[00 w]$ tilt walls indicate that the magnitudes of the Burgers vectors are on the order of 3-4 $\AA$ (see above), which is a fraction of the unit vector of $14 \AA$. This could be explained by the termination of the $14 \AA$ unit layer being divided into steps of the size of one tetrahedral or octahedral sheet (Zwart and Bons. 1987), thus minimizing the core energy of the dislocation. This process is called climb dissociation (Poirier, 1985).

\section{Deformation of chlorite}

Kinks can only be produced without creating voids between layers if slip along the layers is possible; therefore the kinks in chlorite indicate slip along (001). In the example of Fig. 3 the rotation axis is parallel to [100], which indicates slip in the [010] direction. The kink bands in the chlorites are relatively narrow and widely spaced (Fig. 1a), so it can be assumed that most of the slip took place inside the kink band. This slip leads to the development of a high [uv0] dislocation density, while outside the kinkband, where the amount of slip is limited, dislocation density is much lower. Thus it is clear that slip along (001) is accommodated by the generation and movement of [uv0] dislocations. Due to the short Burgers vectors and the low stacking fault energy, movement of these partial dislocations should be relatively easy. This inference is supported by the observed mobility of the dislocations in the microscope; unit dislocations in muscovite are not mobile under these conditions (Silk and Barnes, 1961). In contrast to mica and talc, where the dislocations occur either within the $2: 1$ layer or at the cation layer, the dislocations in chlorite can occur at various levels in the unit layer with equal ease. Thus higher dislocation densities (and therefore higher strains) can be reached. before the dislocations interfere with each other.

A slight curvature of the lattice, as is observed inside the subgrains, is usually associated with moderately high dislocation densities, on the order of $5 \cdot 10^{9} \mathrm{~cm}^{-2}$. Apparently the bending is accommodated by some slip along (001) (flexural slip). If the bending increases, the dislocations pile up in dislocation walls subnormal to (001), thus concentrating the misorientation in a discrete subgrain boundary (glide polygonization).

If the amount of rotation varies in a direction normal to (001), as is often the case because the deforming grain is constrained by its neighbours, the misorientation has to be compensated in some way. In the deformed chlorites the misorientation is accommodated by the formation of subgrain walls subparallel to (001), which is achieved by the generation and/or accumulation of $[00 w]$ dislocations, as has been shown above. By a combination of dislocation glide along ( $h k 0$ ) planes and climb along (001) these dislocation walls can accommodate any amount of misorientation.

If a crystal is to deform plastically while it is constrained by the surrounding grains, at least five independent slip systems are required; this is the Von Mises criterion (see Paterson, 1969). If there are insufficient slip systems available, the stresses will finally exceed the strength of the bonds between the crystal layers and cleavage cracks will occur (Nicolas and Poirier, 1976, p. 44), unless other mechanisms such as diffusion and extensive kinking are active (Paterson, 1969).

In the case of phyllosilicates, there are several easy slip directions in the $(001)$ plane, thus providing two independent slip systems. Other mecha- 
nisms are clearly necessary to allow a general plastic deformation. Most phyllosilicates show extensive kinking, which can increase the number of effective slip systems to a total of four (Paterson, 1969). However, many phyllosilicates cannot provide the required five slip systems and cleavage cracks are common (Bell et al., 1986).

No cleavage cracks have been observed in chlorites, indicating that completely plastic deformation is achieved. There are several mechanisms that either reduce the required number of slip systems or add to the two slip systems that are always present.

The Von Mises criterion applies strictly to homogeneous, constant volume deformation. Pressure solution, although of minor importance in this case, combined with the diffusion processes associated with dislocation climb, will cause volume changes. Furthermore, the deformation is clearly inhomogeneous in all chlorites observed. Therefore less than five slip systems may be sufficient for plastic deformation.

In chlorite there are several mechanisms which add to the two slip systems to achieve plastic deformation. One mechanism is kinking, which is observed in the samples from the Alps, but which is only of minor importance in the slates. Another process is the movement of $[00 /]$ dislocations along $(h k 0)$ planes at high local stresses. Although this system is only activated locally, it is important because it is essential in the formation of subgrain boundaries subparallel to (001). As these boundaries are formed by very closely spaced parallel dislocation lines, they provide easy paths for diffusion, possibly facilitating dislocation climb.

Thus, although there are only two independent slip systems, chlorite can deform plastically; this apparently occurs by a combination of dislocation glide, kinking and diffusion. The two types of chlorite investigated here show essentially the same deformation and polygonization mechanisms, despite the fact that the penninite was deformed under greenschist facies conditions, and the ripidolite was deformed under anchizone (subgreenschist facies) conditions.

\section{Conclusions}

Intracrystalline deformation in chlorite involves a complex polygonization mechanism, which divides the crystal into subgrains bounded by dislocation walls subnormal and subvertical to the (001) plane.

As in other phyllosilicates, the deformation of chlorite is dominated by the (001) slip plane. Slip along this plane is very easy through the generation and movement of (partial) dislocations with $\boldsymbol{b}=[u v 0]$.

After initial bending of the (001) planes through a flexural slip mechanism, accommodated by slip along (001), the misorientation is concentrated in tiltwalls subnormal to (001). These tiltwalls are formed by (partial) dislocations with $\boldsymbol{b}=[u v 0]$.

Tiltwalls subparallel to $(001)$ are formed by arrays of dislocations with a total Burgers vector [001]. These dislocations either nucleate at the grain boundary and move inwards by dislocation climb, or move towards the tip of propagating boundaries by glide along planes inclined to (001); once a boundary is formed the increasing misfit is accommodated by climb of these dislocations along (001).

Due to the combination of very easy slip along (001) and the ability to form subgrain boundaries subparallel to (001) by dislocation climb and the activation of hard slip systems, chlorite deforms plastically even at temperatures as low as $250-350^{\circ} \mathrm{C}$.

\section{Acknowledgements}

I wish to thank Dr. M.R. Drury and Dr. H.L.M. Van Roermund for many stimulating discussions and for their help during the preparation of the manuscript, and Ing. J. Pieters for technical support on the electron microscope. The manuscript was greatly improved by comments from Dr. J. Tullis and Prof. Dr. P. Hartman. Electron microscopy was supported by the Netherlands Organisation for the Advancement of Science ZWO (WACOM), and the Department of Geology. 


\section{References}

Ahn, J.H. and Peacor, D.R., 1985. Transmission electron microscope study of diagenetic chlorite in Gulf Coast argillaceous sediments. Clays Clay Miner., 33: 228-236.

Ahn, J.H., Peacor, D.R. and Essene, E.J., 1985. Coexisting paragonite-phengite in blueschist eclogite: a TEM study. Am. Mineral., 70: 1193-1204.

Ahn, J.H., Peacor, D.R, and Essene, E.J., 1986. Cation-diffusion-induced characteristic beam damage in transmission electron microscope images of micas. Ultramicroscopy, 19: $375-382$

Amelinckx, S. and Delavignette, P., 1962. Dislocations in layer structures. In: J.B. Newkirk and J.H. Wernick (Editors), Direct Observation of Imperfections in Crystals. Interscience, New York, N.Y., pp. 295-356

Bailey, S.W., 1975. Chlorites. In: J.E. Gieseking (Editor), Soil Components. Vol. Il. Inorganic Components. Springer, New York, N.Y., pp. 191-263.

Bailey, S.W., 1980. Summary of recommendations of AIPEA nomenclature committee on clay minerals. Am. Mineral.. 65: $1-7$.

Bailey, S.W. (Editor), 1984. Micas. Rev. Mineral.. Vol. 13. Mineral. Soc. Am., Washington, D.C., 584 pp.

Baronnet, A. and Olives, J., 1983. The geometry of micas around kink band boundaries, I. A crystallographic model. Tectonophysics, $91: 359-373$.

Bell, I.A. and Wilson. C.J.L., 1977. Growth defects in metamorphic biotite. Phys. Chem. Miner., 2: 153-169.

Bell, I.A. and Wilson. C.J.L., 1981. Deformation of biotite and muscovite: TEM microstructure and deformation model. Tectonophysics, 78: 201-229.

Bell, I.A. and Wilson, C.J.L.. 1986. TEM observations of defects in biotite and their relationship to polytypism. Bull. Minéral., 109: 163-170.

Bell, I.A., Wilson, C.J.L., McLaren, A.C. and Etheridge, M.A., 1986. Kinks in mica: role of dislocations and (001) cleavage. Tectonophysics, 127: 49-65.

Bell, T.E., 1986. Microstructure in mixed-layer illite/smectite and its relationship to the reaction of smectite to illite. Clays Clay Miner., 34: 146-154.

Bell, T.H., 1978. Syntectonic nucleation of new grains in deformed mica. Tectonophysics, 51: T31-T37.

Boland, J.N., McLaren, A.C. and Hobbs, B.E., 1971. Dislocations associated with optical features in naturally deformed olivine. Contrib. Mineral. Petrol., 30: 53-63.

Bons, A.J. and Schryvers, D., 1988. High-resolution EM of stacking irregularities in chlorite crystals. Ultramicroscopy. 24: 426 ,

Borg, I. and Handin, J., 1966. Experimental deformation of crystalline rocks. Tectonophysics, 3: 249-368.

Brown, B.E. and Bailey, S.W., 1962. Chlorite polytypism: I. Regular and semi-random one-layer structures. Am. Mineral., 47: 819-850.

Dal Piaz, G.V., Hunziker, J.C. and Martinotti, G., 1972. La Zona Sesia Lanzo e l'evoluzione tettonico-metamorfica delle Alpi Nord-occidentali interne. Mem. Soc. Geol. Ital., 11: $433-466$.
Demny, J. 1963a. Elektronenmikroskopische Untersuchungen an sehr dünnen Glimmerfolien. I. Versetzungen in Glimmer und ibre Kontraste. Z. Naturforsch., A18: 1088-1096.

Demny, J., 1963b. Elektronenmikroskopische Untersuchungen an sehr dünnen Glimmerfolien. II. Das verhalten der Glimmers bei Stärkeren Elektronenbestrahlung. L. Naturforsch., A18: 1097-1101.

Dimberline. A.J., 1986. Electron microscope and microprobe analysis of chlorite-mica stacks in the Wenlock turbidites, mid Wales, UK. Geol. Mag. 123: 299-306.

Edington, J.W., 1975. Interpretation of I ransmission Electron Micrographs. Monographs in Practical Electron Microscopy in Materials Science No. 3. Philips Technical Library-MacMillan, London, 112 pp.

Etheridge. M.A. and Hobbs. B.E., 1974. Chemical and deformational controls on recrystallization of mica. Contrib. Mineral. Petrol., 43: $111-124$

Etheridge, M.A.. Hobbs. B.E. and Paterson, M.S., 1973. Experimental deformation of single crystals of biotite. Contrib. Mineral. Petrol., 38: 21-36.

Etheridge, M.A. Paterson, M.S, and Hobbs, B.E., 1974. Experimentally produced preferred orientation in synthetic mica aggregates Contrib. Mineral. Petrol., 44: 275-295

Gregg. W.J., 1986. Deformation of chlorite-mica aggregates in cleaved psammitic rocks from Islesboro, Maine. U.S.A. J Struct. Geol. 8: 59-68.

Griggs, D.T., Turner, F.J. and Heard, H.C., 1960. Deformation of rocks at $500-800^{\circ} \mathrm{C}$. In: D.T. Griggs and 1. Handin (Editors), Rock Deformation. Geol. Soc. Arn., Mem., 79: 39-104.

Hartevelt, J.J.A., 1970. Geology of the Upper Segre and Valira Valleys. Central Pyrenees, Andorra/Spain. Leidse Geol. Meded. 45: 167-236.

Hey, M.H. 1954. A new review of the chlorites. Mineral. Mag. 30: $277-292$.

Hörz, F., 1970. Static and dynamic origin of kink bands in micas. J. Geophys. Res., 75: 965-977.

Hör, F, and Ahrens. T.J., 1969. Deformation of experimentally shocked biotite. Am. J. Sci, 276: 1213-1229.

Hull, D. and Bacon, D.J., 1984. Introduction to Dislocations. Int. Ser. Mater. Sci. Technol., Vol. 37. Pergamon Press, Oxford, 3rd ed., 257 pp.

Kisch, H.J., 1980. Incipient metamorphism of Cambro-Silurian clastic rocks from the Jamtland Supergroup, Central Scandinavian Caledonides, Western Sweden: illite crystallinity and "vitrinite" reflectance. J. Geol. Soc. London, 137: $271-288$.

Kisch, H.J. 1983. Mineralogy and petrology of burial diagenesis (burial metamorphism) and incipient metamorphism in clastic rocks. In: G. Larsen and G.V. Chilingar (Editors), Diagenesis in Sediments and Sedimentary Rocks, Vol. 2. Develop. Sedimentol., Vol. 25B. Elsevier, Amsterdam, pp. $289 \ldots . .493$.

Knipe, R.J., 1981. The interaction of deformation and metamorphism in slates. Tectonophysics, 78: 249-272.

Kubler, B., 1967. La cristallinité de lillite et les zones tout à fait supérieures du métamorphisme. Etages Tectoniques, Neuchâtel, 105-121. 
Lee, J.H., Peacor, D.R., Lewis, D.D. and Wintsch, R.P., 1984. Chlorite-illite/muscovite interlayered and interstratified crystals: a TEM/STEM study. Contrib. Mineral. Petrol., 88: $372-385$.

Lee, J.H., Peacor, D.R., Lewis, D.D. and Wintsch, R.P., 1986. Evidence for syntectonic crystallization for the mudstone to slate transition at Lehigh Gap, Pennsylvania, U.S.A.. J. Struct. Geol., 8: 767 780.

Mügge, O., 1898. Ueber Translationen und verwandte Erscheinungen in Krystallen. Neues Jahrb. Mineral., Geol. Paläontol., 1: 71-158.

Nicolas, A. and Poirier, J.P., 1976. Crystalline Plasticity and Solid State Flow in Metamorphic Rocks. Wiley, New York, N.Y., 444 pp.

Olives, J., 1985. Interlayer energy for partial slip and cleavage in muscovite. Philos. Mag., A52: 145-152.

Paterson, M.S., 1969. Ductility of rocks. In: A.S. Argon (Editor), Physics of Strength and Plasticity. M.I.T. Press, Cambridge, Mass., pp. 377-392.

Poirier, J.P., 1985. Creep of Crystals: High-Temperature Deformation Processes in Metals, Ceramics and Minerals. Cambridge University Press, Cambridge, 260 pp.

Schneider, M., 1972. Shock-induced mechanical deformations in biotite from crystalline rocks of the Ries crater (Southern Germany). Contrib. Mineral. Petrol., 37: 75-85.

Silk, E.C.H. and Barnes, R.S., 1961. The observation of dislocations in mica. Acta Metall., 9: 558-562.
Speksnijder, A., 1986. Geological analysis of Paleozoic largescale faulting in the South-Central Pyrenees. Geol. Ultraiectina, 43: $210 \mathrm{pp}$.

Spinnler, G.E., Self, P.G., Iijima, S. and Buseck, P.R., 1984. Stacking disorder in clinochlore chlorite. Am. Mineral. 69: 256-263.

Starkey, J., 1968. The geometry of kink bands in crystals-a simple model. Contrib. Mineral. Petrol., 19: 133-141.

Takeuchi, S. and Argon, A.S., 1976. Steady-state creep of single phase crystalline matter at high temperatures. J. Mater. Sci., 11: 1542-1566.

Teichmüller, M., Techmüller, R. and Weber, K., 1979. Inkohlung und Illit-Kristallinität, vergleichende Untersuchungen im Mesozoikum and Paläozoikum von Westfalen. Fortschr. Geol. Rheinl. Westfalen, 27: 201-276

Van der Pluijm, B.A. and Kaars-Sijpesteijn, C.H., 1984. Chlorite-mica aggregates: morphology, orientation, development and bearing on cleavage formation in very-low-grade rocks. J. Struct. Geol., 6: 399-407.

White, S., 1971. Natural creep deformation of quartzites. Nature (London), Phys. Sci., 234: 175-177.

Wilson, C.J.L. and Bell, I.A., 1979. Deformation of biotite and muscovite: optical microstructure. Tectonophysics, 58 . 179-200.

Zwart, H.J. and Bons, A.J., 1987. The structure of grain boundaries in slates. Eos, Trans. Am. Geophys. Union, 68: 1454. 